\title{
VIVER COM ARTE E CULTURA
}

\author{
Eliane Maria Frana ${ }^{1}$, Fabíola Macedo Diass ${ }^{1}$, Gustavo André Pereira de Brito ${ }^{1}$, \\ Thiago Gomes Lopes ${ }^{1}$, Veruska de Araújo Vasconcelos Granja ${ }^{1}$, Elane Fátima \\ Simões $^{2}$ \\ ${ }^{1}$ Graduandos em Lazer e Qualidade de Vida (CEFET-RN) \\ ${ }^{2}$ Professora do CEFET-RN, Mestre (UFSC)
}

Recebido em agosto de 2004 e Aceito em abril de 2005

\begin{abstract}
RESUMO
O presente trabalho foi desenvolvido por alunos do Curso Superior de Tecnologia em Lazer e Qualidade de Vida do CEFET/RN - Centro Federal de Educação Tecnológica do Rio Grande do Norte, em parceria com a APABB - Associação de Pais e Amigos de Pessoas Portadoras de Deficiência dos Funcionários do Banco do Brasil, Núcleo Regional do Rio Grande do Norte, objetivando a promoção de eventos artísticos e culturais. Visando o processo de desenvolvimento das pessoas com deficiência, familiares, amigos e a comunidade em geral, promovendo crescimento individual e grupal, considerando potencialidades artísticas, respeitando limites e valorizando diferenças.
\end{abstract}

Palavras-Chave: Cultura, Lazer e Deficiência.

\section{LIVING WITH ART AND CULTURE}

\begin{abstract}
The present work was developed by students of the Superior Course of Technology in Leisure and Quality of Life of the CEFET/RN - Federal Center of Technological Education of Rio Grande do Norte, in partnership with the APABB - Association of Parents and Friends of People Carrying Deficiency of Bank of Brazil Employees, Regional Nucleus of Rio Grande do Norte, aiming the promotion of artistic and cultural events. The main objective is the development of people with deficiency, familiar, friends and the community in general, by the promotion of individual and group growth, considering artistic potentialities, respecting limits and valuing differences.
\end{abstract}

Key words: Culture, Leisure and Deficiency. 


\section{VIVER COM ARTE E CULTURA}

\section{AÇÃO CULTURAL}

O Conceito de Cultura compreende tudo aquilo que nos cerca, ou tudo o que nos preenche e forma o nosso intelecto, o fruto da nossa inteligência, obras das nossas mãos ou da nossa filosofia, a própria filosofia ou aquilo que realizamos a partir da natureza.

Para D’Ambrosio (1998), "...cultura é tudo aquilo que não é natureza. Por sua vez, toda ação humana na natureza e com a natureza...a terra é natureza, mas o plantio é cultura. As árvores são natureza, mas o papel que delas provém é cultura. Em resumo tudo que é produzido pelo ser humano é cultura." Dentro da cultura encontramos as artes em geral, cujo conceito é definido por D'Ambrosio (1998) como: "Arte é uma interpretação da vida vincula-se a fatores religiosos, políticos, sociais e simbólicos."

Para um objeto ser artístico, ultrapassa o utilitário. Isto significa que satisfaz os cinco sentidos (visão, audição, olfato, paladar e tato), e mais, o espírito (a inteligência) e o coração (a emoção). Os estilos artísticos estão intimamente relacionados a uma época (tempo), lugar (país ou região), estrutura social, econômica, religiosa e política, e à personalidade do artista.

Diante disso, para compreender o que fazer coma arte e a cultura, na sociedade atual surge a ação cultural. Ela surge como uma maneira de promover a distribuição igualitária da cultura e seus benefícios. Segundo Coelho(1989), a ação cultural se caracteriza por dar início a um processo em que o fim não é previsto, nem controlado, ou seja, o conhecimento, os benefícios, tudo que é proporcionado por essas ações são assimilados de modo subjetivo para cada indivíduo, sendo portanto impossível de ser previsto e controlado. Complementando esse pensamento, Francis Jeanson (citado por Coelho, 1989) explica que "um processo de ação cultural resume-se na criação ou organização das condições necessárias para que as pessoas inventem seus próprios fins e se tornem assim sujeitos da ação não seus objetos."

A ação cultural proposta consiste num evento intitulado Viver com Arte e Cultura que objetivou através da sua realização proporcionar às pessoas com deficiência, seus familiares e à comunidade em geral, o acesso a uma proposta de arte e cultura, visando a ampliação de conhecimento em beneficio do desenvolvimento pessoal e social. Para tanto, o evento buscou oportunizar o convívio com artistas profissionais visando estimular valores e talentos; despertar o interesse, a criatividade, a auto-estima da pessoa com deficiência através do exercício das suas próprias qualidades; integrar a pessoa com deficiência nas atividades, considerando suas idéias e pensamentos sobre a proposta formulada; divulgar a arte produzida pelos jovens usuários do Centro de Convivência Crescer (APABB) e artistas locais; proporcionar lazer e recreação; oportunizar a inclusão da pessoa com deficiência na comunidade ampliando suas relações sociais e interpessoais; e ampliar as concepções a cerca da importância e do valor da arte e da cultura como condutoras de melhoria na qualidade dos processos de interações sociais e como mediadora do crescimento social, cognitivo, psicológico e cultural.

Neste sentido, pode-se dizer que o evento foi realizado pelo fato de seus idealizadores compreenderem que a arte e a cultura possibilitam ao sujeito, a participação 
numa realidade contextualizada favorecendo seu desenvolvimento, suas interações com o mundo e sua formação como ser humano. A pessoa com deficiência, em sua condição de sujeito participantes dos processos sociais e culturais, torna-se detentora do direito à inclusão na área das artes e da cultura, considerando-se suas possibilidades de trabalhar a arte como viabilizadora de melhores condições de aprendizagem, de modos de pensar, de ser e de agir.

\section{ARTE E CULTURA: UMA PROPOSTA DE INCLUSÃO}

Através da arte, a pessoa com deficiência, assim como qualquer outro, estabelece relações sociais e culturais, promovendo sua própria construção e visão do mundo. A arte ainda possibilita a inclusão social, que conforme Sassaki (1997, p.3) "É o processo pelo qual a sociedade se adapta para incluir em seus sistemas sociais gerais, pessoas com necessidades especiais e, simultaneamente, estas se preparam para assumir seus papéis na sociedade."

Esse processo de inclusão se faz necessário a medida que há uma parcela considerável de pessoas com deficiência. Segundo estimativas da Organização das Nações Unidas e suas Agências Especializadas, em 1997, pelo menos 10\% da população de qualquer país do mundo sofrem de algum tipo de incapacidade física ou mental, sendo em sua maioria a limitação física, a doença crônica, o retardo mental e as incapacidades sensoriais... Há mais de 400 milhões de pessoas com deficiência no mundo... Rehabilitation of the Disabled - The Social and Economic Implications of Investments for this Purpose (SILVA 1993).

A prática da inclusão social repousa em princípios como: aceitação das diferenças individuais, a valorização de cada pessoa, a convivência dentro da diversidade humana, a aprendizagem através da cooperação. Tomando como base esses princípios, um grupo de alunos do Curso Superior de Lazer e Qualidade de Vida se uniu a APABB - Associação de Pais e Amigos de Pessoas Portadoras de Deficiências dos Funcionários do Banco do Brasil, visando levar aos visitantes a arte e a cultura produzidas por jovens e adultos usuários do Centro de Convivência Crescer, da APABB - RN, bem como pelos artistas da cidade. A parceria deveu-se ao fato de que a Associação promove um trabalho voltado para realização de atividades artísticas e culturais junto aos associados usuários do Centro de Convivência Crescer.

A APABB é uma sociedade civil, sem fins lucrativos. Reconhecida como de utilidade pública federal, com sede em São Paulo, foi fundada por funcionários do Banco do Brasil em 1987, contando atualmente com 15 núcleos em diversas capitais do país e no Distrito Federal, aberta à comunidade desde de 1999, sendo pioneira no desenvolvimento de oportunidades de lazer e recreação para pessoas com deficiência, é referencia nacional nessa área.

No Rio Grande do Norte, o núcleo da APABB está localizado à rua Professor Almeida Barreto, 433 - Lagoa Nova, em Natal/RN, oferecendo aos seus associados, pessoas da comunidade em geral, atividades desenvolvidas através dos programas de Atenção às Famílias e Lazer e Recreação. 
Dentro do programa de Lazer e recreação encontra-se o evento Viver com Arte e Cultura que já conta com duas edições, teve sua primeira edição no dia 08 de maio de 2004 e sua segunda edição no dia 26 de junho de 2004, no horário das 16:00 às 20:00 horas.

A metodologia proposta para o alcance dos objetivos do projeto, constou de uma programação bem diversificada que incluía apresentações artísticas e culturais, exposição de artes, oficinas e brinquedo cantado. Apresentou-se, também, como veículo de inclusão social, uma vez que no mesmo espaço (Centro de Convivência Crescer - APABB - RN) estiveram sendo difundidas as atividades citadas anteriormente, sendo elas desenvolvidas tanto por jovens e adultos, usuários do Centro de Convivência, como também por artistas da cidade do Natal. O público foi constituído de crianças, jovens e adultos portadores de deficiência ou não, sócios ou não da $\mathrm{APABB}-\mathrm{RN}$, familiares, amigos e pessoas da comunidade em geral.

\section{CONSIDERAÇÕES FINAIS}

Atualmente, pode-se perceber que com o advento dos meios de comunicação social as atividades culturais se apresentam com uma certa uniformidade, com um padrão estabelecido de produtos prontos que impedem a criatividade. Essa alienação manifesta-se através da aceitação passiva, sem questionamento às diversas situações ou instituições criadas para atender às necessidades do homem como ser cultural.

Os eventos Viver com Arte e Cultura tiveram o intuito de despertar nos participantes, através das atividades, um contato com a cultura e a arte num processo ativo de transformação e conscientização. As diversas manifestações culturais apresentadas nos eventos foram importantes para a compreensão da cultura em suas quatro dimensões: pessoal e universal, em que os participantes do Centro de Convivência Crescer (APABBRN) apresentaram atrações culturais desenvolvidas e trabalhadas por eles, junto aos educadores do Centro; e a histórico e social através da compreensão e comunicação de sentido que foi dada por cada participante. Este processo é considerado ativo, pois a interpretação, a compreensão de cada atividade desenvolvida no evento é transformada e assimilada pelo indivíduo de maneira subjetiva. Para Laterza, Rios (1971) "Cultura é humanização", ou seja, é uma transformação do mundo paralela a uma transformação do homem.

Como propiciador de uma ampliação das concepções a cerca da importância e do valor da arte e da cultura os eventos proporcionaram aos participantes do Centro de Convivência Crescer a inclusão destes na sua programação. Dessa forma, pode-se constatar através de observações dos educadores do Centro que o trabalho desenvolvido para as apresentações e exposições pôde contribuir a cerca da valorização da arte. Isto deveu-se a contribuição que essas atividades pode proporcionar a esses participantes no desenvolvimento cognitivo, através do conhecimento proporcionado; no desenvolvimento social, através dos laços afetivos criados; no desenvolvimento motor, pois tais atividades exigem dos participantes, muitas vezes, movimentos complexos de serem realizados; no desenvolvimento das qualidades, contribuindo para a auto-valorização dessas pessoas.

Os eventos contaram com artistas, oficineiros e recreadores voluntários que interagiram com os participantes. A metodologia das oficinas permitiu a discussão plena e troca de experiências entre os participantes, estimulada através de exercícios, dinâmicas e 
simulações. A interação tanto dos participantes entre si e destes com os artistas pode ser observada em maior intensidade nesses momentos. Nesse contexto, a inclusão da pessoa com deficiência na comunidade foi efetiva, sem preconceito e sem distinção. As Oficinas eram desenvolvidas simultaneamente e em espaços distintos, os participantes escolhiam a oficina de acordo com a sua preferencia. No decorrer das oficinas, a comunidade, o oficineiro, as pessoas com deficiência e seus familiares interagiam se ajudando na tentativa de desenvolver as atividades propostas.

Esses processos de vivência proporcionados pelas atividades desenvolvidas nos eventos levam ao entendimento da cultura como fenômeno social que traz em si elementos como o lazer e a arte. $\mathrm{O}$ evento caracteriza-se como uma atividade de lazer, já que o lazer é conceitualizado como "um conjunto de ocupações as quais o indivíduo pode entregar-se de livre vontade, seja para repousar, seja para divertir-se, recrear-se e entreter-se ou ainda para desenvolver sua formação desinteressada, sua participação social voluntária, ou sua livre capacidade criadora, após livrar-se ou desembaraçar-se das obrigações profissionais, familiares e sociais" (DUMAZEDIER, 1986, p.46). Observa-se através desse conceito a subjetividade que o lazer traz consigo, deste modo pode-se confirmar que esse evento não faz parte de uma atividade obrigatória do Centro de Convivência, neste aspecto não pode ser considerado uma obrigação. Além disso, o evento se caracteriza como uma atividade que proporciona divertimento, recreação e formação desinteressada.

\section{REFERÊNCIAS BIBLIOGRÁFICAS}

BLASCOVI- ASSIS, Silvana M. Lazer e deficiência mental. Campinas, São Paulo: Papirus, 1997.

COELHO, Teixera. O que é ação cultural. São Paulo: Brasiliense, 1989.

D'AMBROSIO, Oscar. Os pincéis de Deus: vida e obra do pintor Naïf Waldomiro de Deus. Editora UNESP, São Paulo, 1998.

DUMAZEDIER, J. Valores e conteúdos culturais do lazer. São Paulo, SESC, 1986.

LATERZA, M., RIOS, T. A. Filosofia da educação: fundamentos. São Paulo: Herder, 1971.

MARCELlinO, Nelson Carvalho. Estudos do Lazer: uma introdução. Campinas, São Paulo: Autores Associados, $3^{\mathrm{a}}$ ed., 2002.

SASSAKI, Romeu Kazumi. Inclusão: Construindo uma sociedade para todos. $3^{\text {a }}$ ed. Rio de Janeiro: WVA, 1999. 